\title{
Performance Analysis of Water-Water Heat Pump System of 100 kW Scale for Cooling Agricultural Facilities
}

\author{
Youn Ku Kang*, Young Sun Ryou, Jae Kyung Jang, Young Hwa Kim, Jong Goo Kim, Geum Chun Kang \\ Dept. of Agricultural Engineering, National Academy of Agricultural Science, RDA, Suwon 441-707, Korea \\ Received: November $19^{\text {th }}, 2013$; Revised: January $25^{\text {th }}, 2013$; Accepted: February $5^{\text {th }}, 2014$
}

\section{Abstract}

Purpose: In this study, the performance of cooling system with the water-water heat pump system of $100 \mathrm{~kW}$ scale made for cooling agricultural facilities, especially for horticultural facilities, was analyzed. It was intended to suggest performance criteria and performance improvement for the effective cooling system. Methods: The measuring instruments consisted of two flow meters, a power meter and thermocouples. An ultrasonic and a magnetic flow meter measured the flow rate of the water, which was equivalent to heat transfer fluid. The power meter measured electric power in kW consumed by the heat pump system. T-type thermocouples measured the temperature of each part of the heat pump system. All of measuring instruments were connected to the recorder to store all the data. Results: When the water temperature supplied into the evaporator of the heat pump system was over $20^{\circ} \mathrm{C}$, the cooling Coefficient Of Performance(COP) of the system was higher than 3.0. As the water temperature supplied into the evaporator, gradually, lowered, the cooling COP, also, decreased, linearly. Especially, when the water temperature supplied into the evaporator was lower than $15^{\circ} \mathrm{C}$, the cooling COP was lower below 2.5. Conclusions: In order to maintain the cooling COP higher than 3.0, we suggest that the water temperature supplied into evaporator from the thermal storage tank should be maintained above $20^{\circ} \mathrm{C}$. Also, stratification in the thermal storage tank should be formed well and the circulating pumps and the pipe lines should be arranged in order for the relative low-temperature water to be stored in the lower part of the thermal storage tank.

Keywords: Agricultural facilities, Coefficient of performance, Heat pump, Thermal storage tank

\section{Introduction}

The heat pump system is a Heating, Ventilation, Air Conditioning (HVAC) equipment. The system is useful for cooling in summer and heating in winter. It has excellent performance compare to the amount of energy it consumes. Thus, usage of the system as a HVAC equipment is, recently, significantly increasing for cooling and heating in the agricultural facilities and many buildings. It is evaluated by the U. S. Environmental Protection Agency (EPA). The EPA states, "It is low-energy consumption, eco-friendly and the most cost effective system among the current cooling and heating systems for buildings over the world."

\footnotetext{
*Corresponding author: Youn Ku Kang

Tel: +82-31-290-1813; Fax: +82-31-290-1840

E-mail: ykk0977@korea.kr
}

The heat pump system is divided into compression and absorption types. The compression type heat pump system is mainly used, now. The reasons are (1) it is relatively simple to operate and maintain, (2) it has excellent performance. The compression type heat pump system cools and heats by using a compressor, a condenser, expansion valves, an evaporator and a four-way valve, etc. The compression type heat pump system has same components. However, only the heat exchanger type is different due to the different kind of heat source and heat sink. Since the control and operation methods could be different based on the load characteristics of the targeted facilities, it is important to establish the optimum method of operation reflecting the load characteristics. By establishing the optimum method of operation, we can save the power consumption of the heat pump system and improve the 
coefficient of performance. Totally, we can save the heating and cooling cost.

In order to utilize the heat pump system effectively for cooling and heating agricultural facilities, it is necessary to establish design criteria for the load and systemic control must by analyzing the cooling/heating load characteristics of targeted agricultural facilities. After the heat pump system with such design criteria above is made completely, the overall problems should be analyzed with enough trial running. Also, the effective control method of operation should be made.

Usually, PE (Polyethylene) or Glass-coated protected cultivation facilities had an adverse effect on plant growth because the indoor temperature of the facilities in summer rises up to $35 \sim 40^{\circ} \mathrm{C}$ (Kim et al., 2011). Regarding the climate circumstances in Korea, the indoor temperature of a greenhouse rises incredibly in summer. Therefore, it is impossible for crops to grow, normally. As a result, many farmers often stop cultivating during summer. The annual utilization rates of the facilities fell down (Nam, 2000).

The representative cooling methods used in Korea might include cooling using a refrigerator, evaporation, geothermal heat, ventilation and light shading, etc. The cooling method using refrigerator costs a lot because it spends much energy (Kim et al., 2006).

There are studies about promoting growth, increasing the merchandising rates and the number of products by cooling the greenhouses starting with some kinds of higher value-added crops (Yu et al., 2006; Nam et al., 2000; Ryu et al., 1999; Moon, 1999, Lee, 1994; Kim et al., 2011). There are studies about analyses of the cooling effect, the seedling production effect, the power consumption and energy balance of a closed transplant production system (Lee et al., 2006; Kim et al., 2003, 2002). Considering the aspects of the effective usage and the profitability of agricultural facilities, achieving year-round cultivation through the optimization of environment (ex, cooling) inside of greenhouses during summer is a confront subject (Nam, 2000).

In this study, the performance of cooling system with the water-water heat pump system of $100 \mathrm{~kW}$ scale made for cooling agricultural facilities, especially for horticultural facilities, was analyzed. It was intended to suggest performance criteria and performance improvement for the effective cooling system.

\section{Materials and Methods}

\section{Experiment equipments}

The water-water heat pump system of $100 \mathrm{~kW}$ scale used in this study was made for both cooling and heating. The condenser and evaporator were made as a plate type heat exchanger for exchanging heat between refrigerant and water as heat transfer fluids. Refrigerant condenses in the condenser while high-temperature gas phase refrigerant made contacts with water. The water temperature rises while the water penetrates through the condenser. The water is transferred into the PE pipe type heat exchanger as shown in Figure 1. The water gets cooled. Then, the water gets transferred into the condenser again. The water in the thermal storage tank is supplied into the evaporator. The water in the thermal storage tank cools

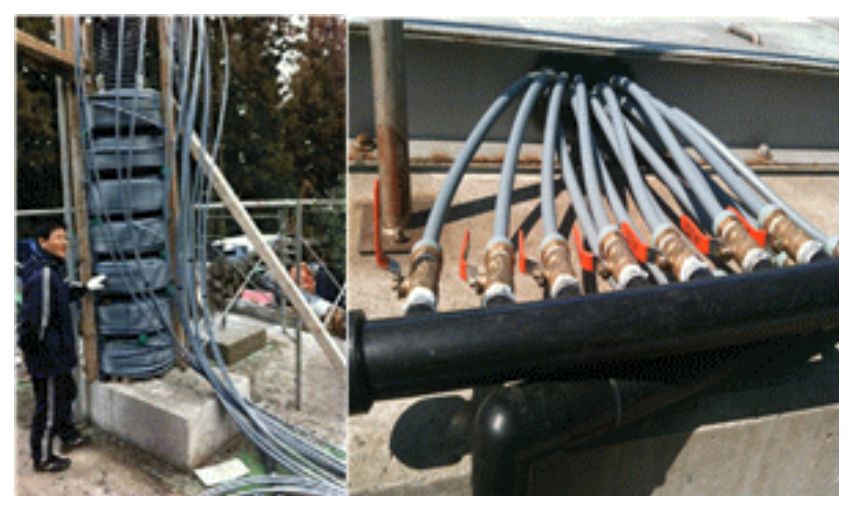

Figure 1. Photo of the PE pipe type heat exchanger.

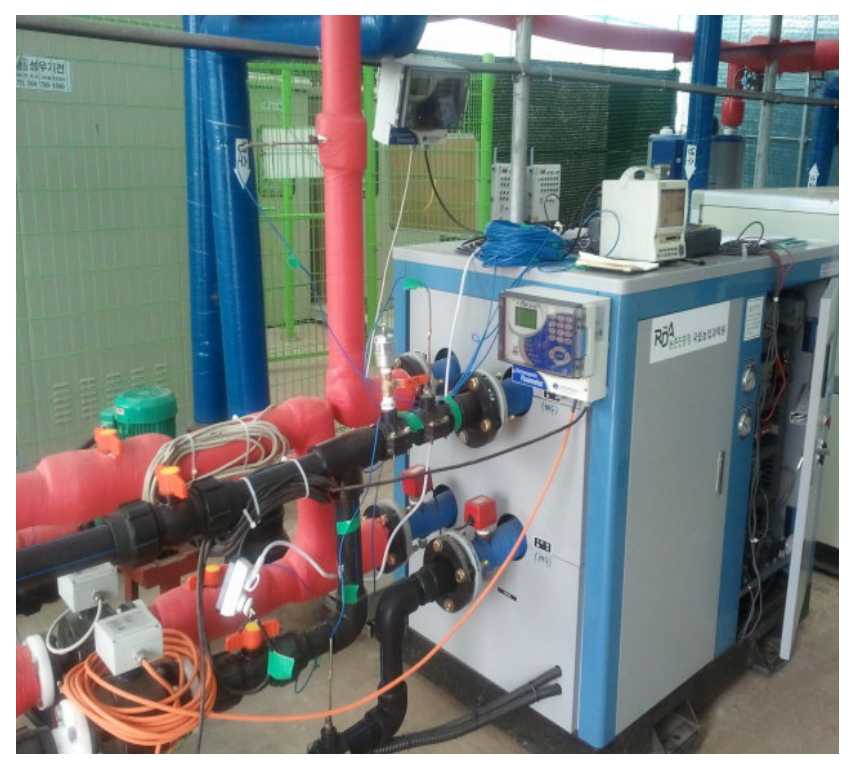

Figure 2. Photo of the water-water heat pump system of $100 \mathrm{~kW}$ scale for cooling performance test. 
gradually while the refrigerant evaporates in the evaporator.

Ryu et al. (2012) suggested the design criteria for the PE pipe type heat exchanger. It has excellent corrosion resistance and low installation costs. In this study, a PE pipe type heat exchanger was, also, made based on the criteria mentioned above. The heat pump system is shown in Figure 2.

\section{Experiment methods}

In order to increase the accuracy of the measurement, the heat pump system was operated longer than 60 minutes to get stabilized. While it was operated continuously for 480 minutes, the data was collected every 10 minutes to analyze the cooling performance.

As shown in Table 1, the measuring instruments consisted of two flow meters, a power meter and thermocouples. An ultrasonic and a magnetic flow meter measured the flow rate of the water as heat transfer fluid. The water exchanged heat with refrigerant in the condenser and the evaporator. A power meter measured electric power in $\mathrm{kW}$ consumed by the heat pump system. T type thermocouples measured the temperature of each part of the heat pump system. All of measuring instruments were connected to the recorder to store all the data.

\section{Results and Discussion}

\section{Temperature changes of the water as heat transfer fluid at the entrances and the exits of condenser and evaporator}

Figure 3 displays the temperature changes of the water at the entrances and the exits of the condenser and the evaporator for 480 minutes. While conducting the cooling performance test, the water temperature at the entrances and the exits of the evaporator became, gradually, lower. The water temperature at the entrances and the exits of the condenser became, gradually, higher.
As shown in Figure 3, the water temperature supplied into the condenser (at the entrance of the condenser) was $27.4^{\circ} \mathrm{C}$ at the beginning of the experiment. After passing through the condenser (at the exits of the condenser), the temperature was $40.2^{\circ} \mathrm{C}$, which increased by $12.8^{\circ} \mathrm{C}$. Later, the water temperature supplied into the condenser tends to rise, gradually. It was because the water supplied into the condenser by the pipe was heated up by sunlight. The experiment was conducted during the daytime in summer. After 480 minutes, the water temperature supplied into the condenser was $33.5^{\circ} \mathrm{C}$. Moreover, after passing through the condenser, it rose up to $44.0^{\circ} \mathrm{C}$, which is increased by $10.5^{\circ} \mathrm{C}$. Comparing with the beginning period of the experiment, the difference between the temperatures before and after the water passing through the condenser was lower by $2.3^{\circ} \mathrm{C}$. The reason was because the water temperature supplied into the evaporator (at entrance of the evaporator) became lower. That is, it was because as the less amount of heat was absorbed from the evaporator, the less amount of heat was discharged to the condenser.

The cooling performance test was conducted after the water temperature in the thermal storage tank was maintained at a constant level. It was designed to form the stratification naturally while the water flows in the

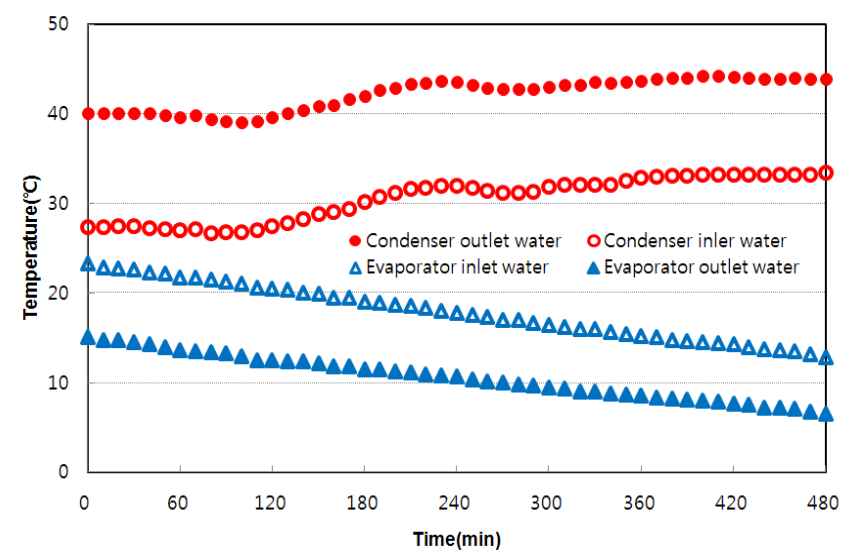

Figure 3. Variation of the water temperature passing through evaporator and condenser.

Table 1. Specifications of the measuring instruments for performance test

\begin{tabular}{cl}
\hline Measuring instruments & \multicolumn{1}{c}{ Specifications } \\
\hline Ultrasonic flow meter & PT868, Panametrics, Norway \\
Electromagnetic flow meter & EF-501, Seoyong Engineering Co., Korea \\
Recorder & MV-200, Yokogawa, Japan \\
Temperature sensors & T type, Daehyeon Tech, Korea \\
Power meter & CW-240, Yokogawa, Japan \\
\hline
\end{tabular}


lower part of the thermal storage tank again after the water flows out from the upper part of the thermal storage tank was cooled by passing through the evaporator.

At the beginning of the experiment, the water temperature in the thermal storage tank was $23.4^{\circ} \mathrm{C}$. Then, it was cooled down to $15.1^{\circ} \mathrm{C}$ while passing through the evaporator. The difference of the temperatures was $8.3^{\circ} \mathrm{C}$. Later, the water temperature in the thermal storage tank became lower, gradually. In 480 minutes, it fell down to $12.9^{\circ} \mathrm{C}$. At that time, the water temperature flowed in the tank after passing through the evaporator was $6.6^{\circ} \mathrm{C}$. The difference between the temperatures of the entrance and the exit was $6.6^{\circ} \mathrm{C}$.

As analyzed above, the temperature difference between the water at the side of the condenser and at the side of the evaporator tended to decrease gradually as time passed by. As the lower the water temperature inside the thermal storage tank, the smaller the temperature difference between the water passing through the evaporator and the condenser at the entrances and the exits.

\section{Power consumption, amount of heat absorbed/discharged and cooling COP}

The power consumption, the amount of heat absorbed from the evaporator, discharged out of condenser and the cooling COP sequentially during the cooling performance test are shown in Figure 4. During the cooling performance experiment, the power consumption was $35.43 \mathrm{~kW}$ at the beginning of the experiment. It tended to increase more or less up to $38.31 \mathrm{~kW}$, later. It was judged that the reason was because the water temperature supplied into the condenser (at the entrance of the condenser) rose. It tended that the amount of heat discharged out of the condenser decreased from $150.33 \mathrm{~kW}$ to $123.31 \mathrm{~kW}$, linearly.

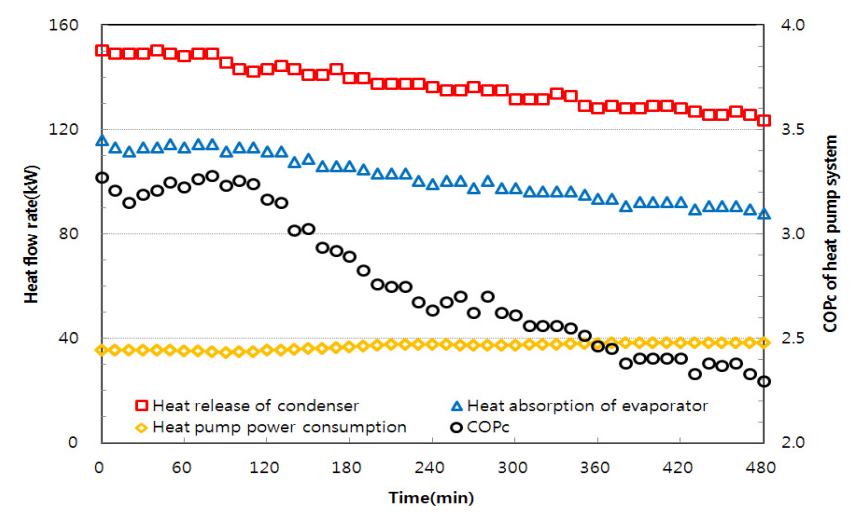

Figure 4. Variation of power consumption, amount of heat absorbed from evaporator and discharged out of condenser and COP.
The amount of heat absorbed from the evaporator, also, decreased from $115.81 \mathrm{~kW}$ at the beginning to $87.91 \mathrm{~kW}$ in 480 minutes, linearly. The amount of heat absorbed from evaporator and discharged out of condenser decrease in similar forms almost in parallel lines

The cooling COP was 3.27 at the beginning, but it decreased down to 2.29 in 480 minutes. The reason was because the water temperature supplied into condenser rose and the water temperature supplied into the evaporator fell (See Figure 3).

\section{Cooling COP based on variation of the water temperature at the entrance of the evaporator}

The cooling COP of the heat pump system is affected significantly by the water temperature supplied into the evaporator from the thermal storage tank. As shown in Figure 5, in case of the water temperature supplied into the evaporator from the tank was higher than $20^{\circ} \mathrm{C}$, the COP exceeded 3.0. However, as the water temperature became lower, the cooling COP became lower, gradually. Therefore, in case of the water temperature was lower than $15^{\circ} \mathrm{C}$, it decreased to the level lower than 2.5 .

Based on the results above, in order to maintain the COP at the level above 3.0, the water temperature supplied into the evaporator from the thermal storage tank should be adjusted to be maintained at the level above $20^{\circ} \mathrm{C}$. Thus, if possible, the stratification in the thermal storage tank should be formed well. Also, after the relative hightemperature water in the upper part of the thermal storage tank was cooled in the evaporator, the circulating pumps and the pipe lines should be arranged in order for the water to be stored in the lower part of the thermal storage tank.

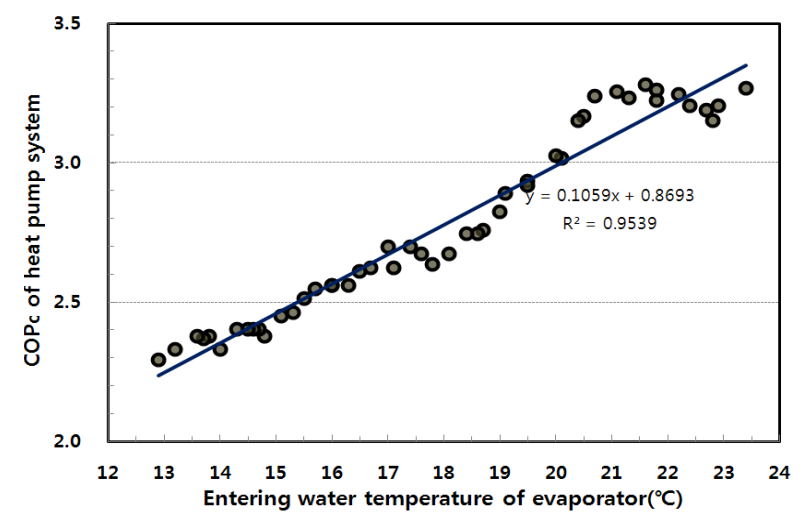

Figure 5. COP variation of the heat pump system according to water temperature entering into evaporator in cooing test. 


\section{Conclusions}

In this study, we analyze the performance of the waterwater heat pump system for cooling agricultural facilities during the high-temperature period in summer. In case that the water temperature supplied into the evaporator was higher than $20^{\circ} \mathrm{C}$, the cooling COP was more than 3.0. In case that the water temperature supplied into the evaporator was lower than $15^{\circ} \mathrm{C}$, the cooling COP fell down at the level below 2.5. As the water temperature supplied into evaporator of the heat storage tank became lower gradually, the cooling COP falls down linearly. Therefore, we suggest that in order to maintain the COP at a high level while cooling operation, the water temperature supplied into the evaporator from thermal storage tank should be maintained higher, stratification in the thermal storage tank should be formed well and the circulating pumps and the pipe lines should be arranged in order for the relative low-temperature water to be stored in the lower part of the thermal storage tank and the relative high-temperature water to be stored in the upper part of the thermal storage tank.

\section{Conflict of Interest}

The authors have no conflicting financial or other interests.

\section{Acknowledgement}

This study was carried out with the support of "Cooperative Research Program for Agricultural Science \& Technology Development (Project No. PJ00841303)", Rural Development Administration, Republic of Korea and "Research Program for Agricultural Science \& Technology Development (Project No. PJ008659)", National Academy of Agricultural Science, Rural Development Administration, Republic of Korea.

\section{References}

Kim, K. D., E. H. Lee, W. B. Kim, J. G. Lee, D. L. Yoo, Y. S. Kwon, J. N. Lee, S. W. Jang and S. C. Hong. 2011. Effects of several cooling methods and cool water hose bed culture on growth and microclimate in summer season cultivation of narrowhead golden ray (Ligularia stenocephaia). Journal of bio-environment control 20(2): 116-122 (in Korean, with English abstract).

Kim, J. K., Y. H. Kim, M. G. Lee, Y. H. Choi and S. H. Lee. 2003. Analysis of electric energy consumption in closed transplants production system as affected by photoperiod and relative humidity. Conference of the Korean society of Agricultural Machinery 2003:145-150 (in Korean, with English abstract).

Kim, J. K., Y. H. Kim and S. H. Lee. 2002. Analysis of energy balance in closed transplants production system. Conference of the Korean society of Bio-Environment Control 2002:326-331 (in Korean, with English abstract).

Lee, J. H. 1994. Effect of root zone warming by hot water in winter season on rhizosphere environment, growth and yield of greenhouse-grown cucumber (cucuis sativus L.). PhD Diss. Daegu, Kyoungbook: Kyungpook National University, Department of horticultural science (in Korean, with English abstract).

Moon, J. H., S. K. Lee and D. K. Ko. 2000. Effect of root zone cooling in summer season on yield and quality. Report of national horticultural research institute: 45-48 (in Korean)

Nam, S. W. 2000. Actual utilization and thermal environment of greenhouses according to several cooling methods during summer Season. Journal of bio-environment control 9(1):1-10 (in Korean, with English abstract).

Nam, Y. I. 2000. Automatic system of hydroponic culture and production facility. Suwon: Teaching material of R. D. A. (in Korean).

Yu, I. H., Y. I. Nam, T. Y. Kim, M. Y. Roh and M. W. Cho. 2006. Effect of newly developed fan and mist evaporative cooling system on greenhouse cooling and growth of cucumber. Journal of Bio-Environment control 15(1): 91-97 (in Korean, with English abstract).

Ryu, Y. S., J. T. Chang, Y. J. Kim, K. J. Lee and J. H. Yun. 1999. Performance test of heat pump system for low temperature treatment of Phalaenopsis. Conference of the Korean society of Bio-Environment Control 99: 95-99 (in Korean).

Ryou, Y. S., Y. K. Kang, J. K. Jang, Y. H. Kim, J. G. Kim and G. C. Kang. 2012. Heat exchanger design of a heat pump system using the heated effluent of thermal power generation plant as a heat source for greenhouse heating. Journal of Bio-Environment Control 21(4): 372-378 (In Korean, with English abstract). 